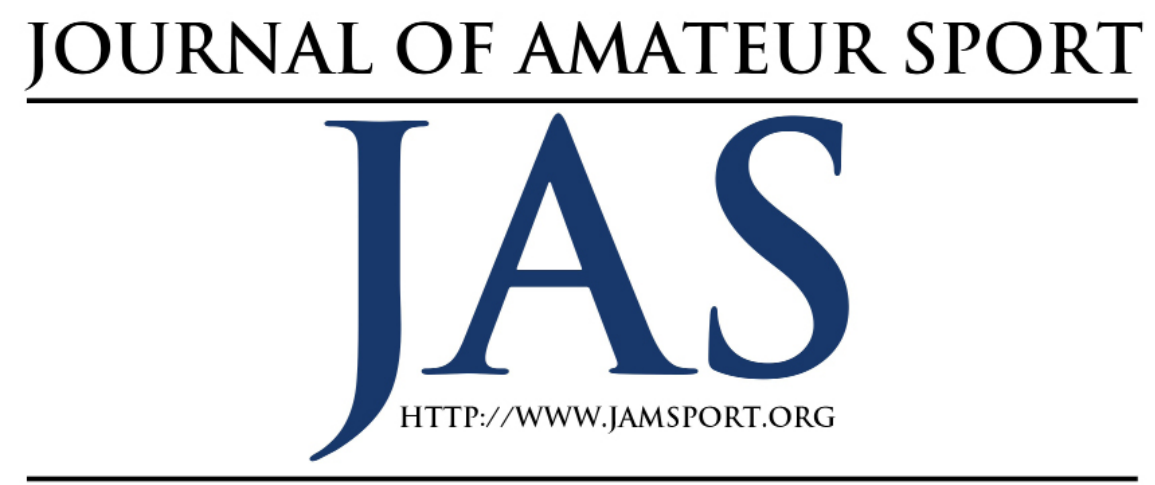

\title{
Factors Influencing College Selection by NCAA Division III Men's Basketball Players
}

\author{
Brett A. Nichols ${ }^{1}$ \\ Mark A. Smith ${ }^{2}$
}

Megan Babkes Stellino

\section{${ }^{1}$ University of Northern Colorado ${ }^{2}$ Missouri State University}

\begin{abstract}
National Collegiate Athletic Association (NCAA) Division III basketball coaches are often faced with the challenge of stretching resources to successfully recruit athletes who will represent the institution without the benefit of athletic scholarships. Understanding the factors that influence the college selection of NCAA Division III athletes might assist these coaches in more efficiently maximizing their resources. The purposes of this study were to (a) examine specific factors which influence why DIII basketball players made their choice to attend a particular school, (b) determine if there were differences based upon the type of school attended, and (c) examine whether there were categorical factors that differed on the basis of a players recruitment, year in school, race/ethnicity, playing status, or financial aid status. Using the revised Influential Factors Survey for Student Athletes (IFSSA-R; Pauline, 2010), DIII men's basketball players $(\mathrm{N}=503)$ were surveyed. Responses indicated that 'career opportunities' was the most vital item associated with college selection. With regard to the five categorical factors (academic, athletic, coaching staff, financial aid, and social atmosphere), academic factors were also found to be important. Analyses revealed significant $(p<.05)$ differences as determined by type of school for the athletic, academic, and financial aid subscales. Results of the study provide useful information for DIII men's basketball coaches and college administrators throughout various points in the recruitment and college selection process.
\end{abstract}


$\mathrm{I}$ n college athletics, the process of recruiting college athletes is both complex and competitive. Recruiting in college basketball takes considerable time and financial resources (Treme, Burrus, \& Sherrick, 2011). At the National Collegiate Athletic Association (NCAA) Division III (DIII) level most sports have fewer coaches, and significantly reduced financial and budgets compared to scholarship Division I (DI) programs. As a result, recruiting DIII athletes is a cumbersome and exhausting process that simply never ends (Johnson, 2010). However, as is the case in DI, DIII coaches are challenged by having similar recruiting processes. The fact that DIII does not allow athletic scholarships means that DIII coaches are challenged to recruit athletes to a school without the offer of any kind of athletically driven financial aid.

Also exacerbating the problem is that DIII has the greatest variation in types of schools, with small liberal arts colleges with less than 1,000 students competing against state schools and national universities with as many as 50,000 students. Unlike DI Coaches, DIII coaches are faced with finding student-athletes who choose to play their sport while paying for their college education. Coaches compete with other coaches from an enormous range across school type and size. This unique environment for recruiting makes DIII important to examine with regards to college selection so that in the future coaches can maximize efficiency during the recruiting process. DIII men's basketball coaches are also often recruit- ing against schools with athletic scholarships for the best players. To date there is a paucity of research that focuses on the intricacies of recruiting at the DIII level.

\section{Intercollegiate Athletic Recruiting}

Coaches, administrators, and researchers have attempted to understand effective recruiting practices in college athletics for more than fifty years (i.e. Behling, Labovitz, \& Gainer, 1968; Konnert \& Giese, 1987). In intercollegiate athletics recruiting has been examined from many perspectives including how coach characteristics influence recruits' decisions (Magnusen, Kim, \& Perrewe, 2014), the relationship between winning and recruiting (Caro, 2012), recruiting effectiveness (Magnusen, Kim, McAllister, Perrewe, $\&$ Ferris, 2018) and factors influencing athletes' college selection (Czeckanski \& Barnhill, 2015; Day, 2011; Magnusen, Kim, Perrewe \& Ferris, 2014; Mathes \& Gurney, 1985; Pauline, 2010; Pauline, Pauline, \& Allen, 2008; Pauline, Pauline, \& Stevens, 2004; Rhee, Barnes, Kim, \& Carroll, 2018).

In DI athletics there are a number of factors that have been connected with recruiting efforts. In several Power Five football conferences, Caro (2012) found that between $63-80 \%$ of team's success could be attributed to recruiting. Other findings in DI athlete recruitment include connecting recruiting success with positive performance outcomes (Dumond, Lynch, \& Plantania, 2008; Evans \& Pitts, 2017); reputation matters to athletes (Magnusen et al., 2018); past coaching 
success impacts recruiting (Treadway et al., 2014); and post season success, and academic rankings have been associated with success in intercollegiate athlete recruitment (Magnusen et al., 2017). DI recruiting research has become flooded with studies that have examined a variety of factors that play a role in athlete recruitment from a largely economic standpoint (Evans \& Pitts, 2017; Harris, 2018; Rhee et al., 2018).

Magnusen and colleagues (2014b) developed a social influence model to describe the recruiting process in NCAA sports. In this model, recruiters' social effectiveness characteristics along with recruiting strategies influence a recruits' perception of fit. Influential agents also have a perception of fit that can be influenced by various recruiting strategies. Perceptions of these agents and the recruits then ultimately influence recruiting outcomes. The model suggests the importance of coaches in the recruiting process and specifically future exploration of personality characteristics of these coaches and their impact to recruiting outcomes (Magnusen et al., 2014b).

\section{Factors in College Selection}

Research focused on student-athletes' navigation of the college selection processes university would help coaches' recruitment endeavors (Pauline, 2010). The relevance of high school athletes' decision-making with regards to college selection and the importance of coaches in these processes has been understood, yet a variety of findings exist with re- gard to what athletes value most as they consider selecting a collegiate athletic program (Czeckanski \& Barnhill, 2015; Magnusen, Kim, Perrewe \& Ferris, 2014). Various studies have focused on creating a way to assess and evaluate the college selection process for student-athletes (Czeckanski \& Barnhill, 2015; Doyle \& Gaeth, 1990; Pauline et al., 2004). Instruments have been developed to examine college choice between non-athletes and athletes (Gabert et al., 1999); measure attributes influencing college decisions (Judson, James \& Aurand, 2004); explore influential college selection factors; and to examine college choice factors across NCAA divisions (Influential Factors Survey for Student Athletes - Revised, IFSSA-R, Pauline, 2010).

In the most recent review of research on athletes' college selection, the findings were summarized into three categories: (1) athletic program factors, (2) academic factors, and (3) external factors (Magnusen et al., 2014b). Numerous studies have found the most important athletic program factor to be the recruiter or coach (Goss, Jubenville, \& Orejan, 2006; Letawsky, Schneider, Pedersen, \& Palmer, 2003; Kankey \& Quarterman, 2007; Mathes \& Gurney, 1985; Pauline, 2010). Gabert and colleagues (1999) found coaches to be the most important in different levels of college sport, though not in DIII. Other athletic factors that have been found to play a key role in athlete recruitment are the opportunity for playing time (Goss et al., 2006; Konnert \& Giese, 1987; Pauline et al., 2004; Stot- 
lar, 1976) and athlete facilities (Dumond, Lynch, \& Plantania, 2008; Letawsky et al., 2003; Pauline et al., 2007; Rhee et al., 2018).

The three most important academic factors that have been found to be most important for athletes' college selection include academic majors, academic reputation of the school, and post-graduation career opportunities (Magnusen et al., 2014b). Among the studies that reported availability of major is the most highly rated factor in college selection for athletes, Pauline and colleagues (2008) found this to be the case for DI, DII, and DIII softball players. Other research has indicated that this is one of the top factors for student-athletes (Goss et al., 2006; Judson et al., 2004; Konnert \& Giese, 1987). The academic reputation of a school has also been found to positively influence athlete college selection (Magnusen et al., 2018; Pauline, 2010). Additionally, career opportunities after graduation are important to athletes in their college selection (Kankey \& Quarterman, 2007; Pauline, 2010).

The third category of characteristics in the most recent review of athlete college selection factors was external factors including, geographic location, economic conditions, and weather and climate (Magnusen et al., 2014b). Less consensus has been found with these factors. In 2008, Dumond et al. found DI football players described that school location was the most important factor in their choice, while DI-DIII lacrosse players only viewed this as moderately important (Pauline, 2010).

\section{Division III Recruiting}

College selection and student-athlete recruitment are both important especially within the context of DIII athletics. Research on the "last bastion of pure amateur college athletics" (Schrotenboer, 2012), lacks significant depth of exploration. Considering that in 2017-18 there were 190,900 student-athletes in DIII, most of whom do not go on to play sports beyond college (NCAA Recruiting Facts, 2018), the classification of sport deserves greater consideration and understanding. DIII athletics has been examined in relation to organizational outcomes (Fink, Pastore, \& Riemer, 2003) and a handful of sports have been investigated from perspectives which include, in season body composition, strength, and power among wrestlers (Schmidt, Piencikowski, \& Vandervest, 2005), differences in factors influencing college selection across NCAA Divisions I, II, and III in lacrosse athletes (Pauline, 2010), and factors influencing the college selection of baseball (Pauline et al., 2004) and softball players (Pauline et al., 2008), and men's basketball and football players (Konnert \& Giese, 1987). Increased coverage and notoriety of all levels of college basketball has even landed DIII schools in the news reporting their recruiting practices (Alger, 2013; Galleske, 2012; Johnson, 2010), yet there is no research to support recruiting practices or 
outcomes in DIII men's basketball. Konnert and Giese (1987), in a comparison of DIII men's basketball and football players to non-student athletes, did find that the top reasons that athletes chose their school were for a specific academic program and the opportunity to play varsity athletics.

The structure of the recruiting process for DIII coaches is such that many individuals who have not played, coached, or worked directly with DIII athletics have difficulty understanding what DIII coaches face. DIII coaches spend so much time recruiting future student-athletes that hands on coaching seems like a comparatively small part of their job (Johnson, 2010). Even when recruiting does end, DIII coaches never really know who will matriculate the next fall until the recruits show up for classes (Hambleton, 2010). This differs from DI where coaches know which players will attend the following season as signed scholarship offers act as official enrollment agreements. DIII schools do not have similarly binding agreements.

While every DIII school has its' own strengths and challenges with recruiting, DIII coaches at many levels frequently look at recruiting as a numbers game. As a result, coaches who might be looking for five new players for next season might need two or three times that number to be accepted to the school in order to get five to matriculate. In order to have fifteen players admitted at a competitive DIII school, a coach might need 30-50 applicants. In order to get even
30 applicants, a particular coach might need to have more than 100 active and involved recruits. Over the course of the previous year, in order to have that many active recruits, as many as 200 prospects are often engaged through various methods of communication. At times, it seems in DIII men's basketball that every recruiting cycle starts with a vast number of players (Alger, 2013). For DIII men's basketball programs that usually have one full-time head coach and one full- or part-time assistant, this number of active recruits can become overwhelming to manage. The challenge to recruit large numbers of players as described above has been reported in DIII volleyball (Pennington, 2006), and the "numbers game" is well understood among DIII coaches at many schools and in many sports.

A more commonly viewed perception of recruiting in intercollegiate athletics is the result of media coverage on DI sports where coaches recruit to fill their open scholarships. In DI, basketball coaches spend each summer, supported by their institutions, following their top prospects from tournament-to-tournament hoping to finalize a short list of potential players deserving of a scholarship offer, or courting players who have already received such an offer. In contrast, DIII basketball coaches often go to the same tournaments in their own cars, staying in cheap hotels or on couches, and have no athletic scholarship to offer even the best players (Hambleton, 2010; Johnson, 2010, Kane, 2009). Fur- 
ther exacerbating this challenge for DIII coaches is that their programs are typically limited to either one or two "full-time" coaches, while DI basketball programs often employ the maximum number of recruiters allowed: four (NCAA Division I Manual, 2018), and have a director of basketball operations.

The challenge for DIII men's basketball coaches becomes identifying, and recruiting, the right student athletes to maximize time and efforts while attracting athletes who are the best fit for ones' program. However, without athletic scholarships, and the need for large numbers of recruits, DIII basketball recruiting presents a unique combination of challenges, which remain poorly understood and largely unexplored in the literature. As is often the case at DIII schools even recruits who claim to be very interested fail to apply, or choose to go to other, specifically larger, institutions where being a college athlete is not an option. For every school, the circumstances that describe their recruiting environment varies based upon academic standards, university/athletics department mission statements, application deadlines, and a host of other factors. Nevertheless, spreading a limited number of resources (i.e. time, personnel, financial) to the important component of recruiting is a challenge. Coaches who maximize their resources and minimize time spent on non-applicants place themselves in a better position to be successful. Being able to translate effective resource management into having greater knowledge about why student-athletes choose a college, can enhance recruiting outcomes (Pauline, 2010).

To date there has been no published research focused on evaluation of the factors that influence the college selection of NCAA DIII basketball players. Furthermore, no research has been published that includes data that identifies characteristics about basketball players that can help coaches determine which players in the recruiting process are more likely to attend a DIII school and persist for four years. The objective of this study was to advance the knowledge on athletes' college selection within the unique and underexamined environment of DIII athletics. The purposes of this study were to (a) examine the specific factors that influence why DIII basketball players made their choice to attend a particular school, (b) determine if there were differences based upon the type of DIII school they attended, and (c) examine whether there were categorical factors that differed on the basis of a players recruitment, year in school, race/ ethnicity, playing status, or financial aid status.

\section{Methods}

\section{Participants}

While this problem is relevant to all coaches at DIII, a convenience sample of men's basketball players was examined to begin exploring these purposes at the DIII level. The participants were male NCAA Division III basketball student-athletes $(\mathrm{N}=503)$ on teams located 
across the country during the 2013-14 season. The geographically diverse sample included participants from 37 schools in 15 states, 15 conferences, and eight NCAA DIII regions. Participants also represented seven different types of schools: Regional Universities $(n=148)$, other National Liberal Arts Colleges $(n=$ 92), selective National Liberal Arts Colleges $(n=82)$, Top 25 National Liberal Arts Colleges $(n=78)$, highly selective National Universities $(n=43)$, Regional Colleges $(n=30)$, and National Universities $(n=30)$. The average age of the participants was 19.90 years $(\mathrm{SD}=1.29)$. Over two-thirds of the participants ( $n$ $=362 ; 72 \%)$ self-identified as Caucasian, and $19.7 \%$ as African-American $(n$ = 99). Participant self-reported playing status varied greatly, with $30.4 \%$ considering themselves starters, $28.2 \%$ regular substitutes or occasional starters, $18.3 \%$ described being sporadic players who sometimes played in games, and $22.3 \%$ of players reported being practice players who did not play in games. With regard to their recruitment, $37 \%$ of the participants were recruited by 2-5 programs, $29.6 \%$ said to have been moderately recruited (5-10 teams), 22.1\% believed they were highly recruited (more than 10 teams), $4 \%$ were exclusively recruited by their current team, and 7.4\% reported being non-recruited walk-on players. Participants also self-reported their financial aid status. The majority reported having some loans/financial aid $(n=372)$, while others reported paying full tuition $(n=$ 115), with a small minority reporting attending school on a full need-based or academic scholarship $(n=16)$.

\section{Measures}

IFSSA-R. To measure various factors influencing their college selection, all participants completed the IFSSA-R (Pauline, 2010). The IFSSA-R consisted of 53 items with responses indicated on a 5-point Likert-type scale, with 1 representing not important and 5 representing extremely important. Participants were prompted with the stem, How important were each of the following items in the selection of the school that you currently attend? Two items were removed from the IFSSA-R as they did not apply to the current study (NCAA Division (I, II, or III) affiliation and Amount of Athletic Scholarship), resulting in a 51-item survey. The IFSSA-R used was comprised of five different subscales: athletic, academic, social atmosphere, coaching staff, and financial aid. Mean scores were calculated for each of the five subscales. Though the IFSSA-R was not initially created to examine men's basketball, previous research has shown that the college selection subscales used in this study are within acceptable levels of internal consistency among the scales (Pauline et al., 2004).

Demographic survey. Athletes completed a short self-report demographic survey that included age, current year in school, race/ethnicity, financial aid status, current playing status (starter, regular sub, reserve player, or practice player), and how many schools recruited them. The school name was tracked during the 
data collection process and the type of school was included as an independent variable during analysis. The categories from the annual US News \& World Report college selection issue were used to classify the schools into one of seven types of schools: Top 25 National Liberal Arts Colleges, Selective National Liberal Arts Colleges, Other National Liberal Arts Colleges, National Universities - High Selective, National University, Regional Colleges, and Regional Universities. US News \& World Report uses the mission statements and Carnegie Classification system to categorize and rank schools in four groups: National Universities, National Liberal Arts Colleges, Regional Universities, and Regional Colleges (Morse, Brooks, \& Mason, 2017). For this study, three additional groups were created: Top 25 Liberal Arts Colleges, Highly Selective Liberal Arts Colleges (HSLAC ranked 26-50), Highly Selective National Universities (HSNU ranked 1-25), and National University (NU ranked 26 or lower) as the cost of attendance and competitive nature of admission often vary between these groups.

\section{Procedures}

After receiving university IRB approval, 150 NCAA Division III head men's basketball coaches were contact via email about participating in the study. The email provided coaches with a concise explanation of the study, its purpose, and a detailed outline of their teams' potential participation. Forty-eight coaches agreed and athletes from 37 schools completed surveys. Wherever possible data were collected in person. However, given the geographically diverse sample, a survey packet with instructions was also postal mailed to a number of schools. The packet included a cover letter, a survey for each athlete, a self-addressed stamped envelope, and a set of instructions. Copies of a non-signature consent forms were also provided and distribute to each basketball player prior to the beginning of the survey. The coach facilitating was instructed that no members of the coaching staff or athletics administration were to be present during the research so as not to influence inadvertently or otherwise, any answers from his players. Among the 48 schools whose coaches agreed to participate, 774 surveys were distributed, with 531 surveys returned for a response rate of $68.6 \%$. Removing the 183 surveys mailed to coaches who never responded the actual response rate was $89.8 \%$.

\section{Design and Data Analysis}

The study involved a cross-sectional survey method designed to provide information about the factors that affected college selection by current NCAA DIII men's basketball players. The data were tested for normality, using skewness and kurtosis values, univariate outliers, and simple correlations. All incomplete surveys were removed, and 28 surveys were also removed for satisficing (i.e. non-differentiation of answers). For each of the five IFSSA-R survey categories descriptive statistics were calculated. In addition, 
means and frequencies were calculated for each of the 51 survey questions (see Table 1). The five IFSSA-R subscales were also tested for subscale reliability. The primary statistical analysis occurred through testing numerous one-way multivariate analysis of variance (MANOVA) with the five categories from the IFSSA-R as dependent variables (academic, athletic, financial aid, social atmosphere, and coaching staff), and the collected demographic data as independent variables (i.e. type of school).

\section{Results}

The overall purpose of this study was to examine factors that influence why NCAA Division III men's basketball players chose their current school. Using the ranked mean (see Table 1), the top four factors were all academic with career opportunities number one. Four out of the remaining top 10 were from the social atmosphere category, and the only athletic factor in the top 10 was the head coach. Three of the four least influential factors were athletic factors.

The five college selection subscales (athletic, academic, social atmosphere, coaching staff, and financial aid), were each tested for normality, correlations, and the factorial reliability. Table 2 reveals acceptable Cronbach's (1951) alpha levels $(\alpha>$.70; Nunnally, 1978) for each of the subscales. Mean scores for each of the five college selection categories were also calculated. The academic category had the highest mean score and was closely followed by financial aid
(Table 2.). The lowest mean among the five categories was athletic, which indicated that factors like a team's schedule, sponsorships, media coverage, and even facilities may have been limited in the decision-making process for these athletes.

A MANOVA was conducted to examine the differences among factors used in college selection (athletic, academic, etc.) according to type of school attended, a. Results revealed significant differences between the five different categories according to the type of school (Wilks' $=.03, F(5,492)=2.77$, $\mathrm{p}<.000)$. Between-subjects effects test revealed that significant differences $(\mathrm{p}$ $<.05)$ existed among three categories: athletic $(F(6,496)=2.42, \mathrm{p}<.026)$, academic $(F(6,496)=2.32, \mathrm{p}<.032)$, and financial aid $(F(6,496)=6.45, \mathrm{p}<.000)$. Regarding the athletic decision-making factor, basketball players at Selective National Liberal Arts Colleges were significantly less concerned with athletic factors then all other basketball players. Contrastingly, basketball players from Regional Colleges were significantly more concerned with athletic factors as a part of their decision-making process.

The second subscale that revealed significant differences between categories was academic. Players at Regional Universities were significantly less concerned with academic factors than were all participants from other types of colleges/universities. In contrast, players at National Universities rated academic factors as significantly more important in their decision-making process than other 
Table 1

Mean Scores for Each Factor on the Influential Factors Survey for Student-Athletes Revised (IFSSA-R; Pauline, 2010) $N=503]$

\begin{tabular}{|c|l|c|}
\hline Rank & \multicolumn{1}{|c|}{ Item Description } & Mean Score \\
\hline 1 & Career Opportunities (AC) & 4.30 \\
\hline 2 & Academic Reputation of College/University (AC) & 4.29 \\
\hline 3 & Reputation of Academic Program/Major (AC) & 4.14 \\
\hline 4 & School Offers Your Specific Major of Interest (AC) & 4.09 \\
\hline 5 & Overall Reputation of College/University (SA) & 4.08 \\
\hline 6 & Social Atmosphere of the Team (SA) & 3.97 \\
\hline 7 & Head Coach's Personality/Style (CS) & 3.94 \\
\hline 8 & Campus Visit (SA) & 3.76 \\
\hline 9 & Campus (SA) & 3.76 \\
\hline 10 & Opportunities for Financial Aid (FA) & 3.75 \\
\hline 11 & Opportunity to Win Conference/National Title (AT) & 3.74 \\
\hline 12 & Overall Cost to Attend the University (FA) & 3.71 \\
\hline 13 & Total Amount of Financial Aid Offered (FA) & 3.70 \\
\hline 14 & Graduation Rate of Student-Athletes (AC) & 3.64 \\
\hline 15 & Basketball Specific Facilities/Resources (AT) & 3.61 \\
\hline 16 & Opportunity to Play Early in Career (AT) & 3.57 \\
\hline 17 & Reputation of Coaching Staff (CS) & 3.56 \\
\hline 18 & Academic Facilities (i.e. computer labs, library, classrooms) (AC) & 3.55 \\
\hline 19 & Athletic Department Facilities/Resources (AT) & 3.54 \\
\hline 20 & Coaching Staff's Time Spent Recruiting You (CS) & 3.47 \\
\hline 21 & Tradition of Team (AT) & 3.46 \\
\hline 22 & Parents (SA) & 3.41 \\
\hline 23 & Amount of Playing Time (AT) & 3.41 \\
\hline 24 & Team's Win/Loss Record (AT) & 3.41 \\
\hline 25 & Social Environment at University (SA) & 3.37 \\
\hline 26 & Faculty at the University (AC) & 3.34 \\
\hline 27 & Assistant Coach(es) (AT) & 3.31 \\
\hline 28 & Amount of Academic Scholarship Offered (FA) & 3.25 \\
\hline 29 & Proximity/Distance of University from Home (SA) & 3.15 \\
\hline 30 & Support Services for Student-Athletes (AC) & 3.05 \\
\hline 31 & Regional Location of University (SA) & 2.99 \\
\hline 32 & Size of University (SA) & 2.97 \\
\hline 33 & Tradition of Athletic Department (AT) & \\
\hline 34 & Team's Schedule (AT) & \\
\hline & & \\
\hline
\end{tabular}


Table 1 (continued)

\begin{tabular}{|c|l|c|}
\hline Rank & \multicolumn{1}{|c|}{ Item Description } & Mean Score \\
\hline 35 & Conference Affiliation of Team (AT) & 2.95 \\
\hline 36 & Know Athletes on the Basketball Team (SA) & 2.92 \\
\hline 37 & Promises Made by Coaches During the Recruiting Process (CS) & 2.91 \\
\hline 38 & Head Coach's Years at the Institution (CS) & 2.86 \\
\hline 39 & Team Travel Locations (AT) & 2.83 \\
\hline 40 & Housing (SA) & 2.82 \\
\hline 41 & Fan Support of Team (AT) & 2.66 \\
\hline 42 & Have Friends at the University (SA) & 2.59 \\
\hline 43 & Extracurricular Activities (i.e. fraternities, intramurals, clubs) (SA) & 2.55 \\
\hline 44 & Athletic Department or Team Website (AT) & 2.53 \\
\hline 45 & Know Athletes at the University (SA) & 2.53 \\
\hline 46 & High School Coach (CS) & 2.49 \\
\hline 47 & Affiliation of the University (i.e. religious, private, public) (SA) & 2.34 \\
\hline 48 & Team Sponsorships (AT) & 2.19 \\
\hline 49 & Ethnic and/or Gender Ratio of the University (SA) & 2.10 \\
\hline 50 & Media Coverage (AT) & 1.94 \\
\hline 51 & Number of Alumni in Professional Sports (AT) & 1.73 \\
\hline
\end{tabular}

participants at college/university groups different than National Universities. Lastly, basketball players at Top 25 National Liberal Arts Colleges were significantly less concerned with financial aid as a decision-making factor than any of the other participants.

The third purpose was to examine the five categorical college selection factors with regard to year in school, playing status, financial aid status, and race/ethnicity. MANOVA results revealed significant differences between the five different categories according to players' reported financial aid status (Wilks' $=.09, F(5$, $496)=17.85, \mathrm{p}<.000)$. Between subjects effects tests for financial aid status revealed significant differences $(\mathrm{p}<.05)$ existed among two of the college selection categories: financial aid $(F(2,500)=$ $72.07, \mathrm{p}<.000)$, and coaching staff $(F(2$, $500)=3.51, \mathrm{p}<.031)$. Basketball players who reported receiving a full non-athletic scholarship placed a significantly higher value on financial aid in the college selection process as opposed to the other two groups. Significant group differences existed between players who reported being full pay athletes, in that financial aid was not important in their college selection. A third group of players, who reported having some loans/financial aid reported financial aid to be significantly more important than full-pay athletes, yet significantly less important than those who were full-need athletes. 
Table 2

Reliability/correlation table for NCAA DIII basketball players $(N=503)$ according to five college selection criteria

\begin{tabular}{lccccc}
\hline \multicolumn{1}{c}{ Variable } & $\mathbf{1}$ & $\mathbf{2}$ & $\mathbf{3}$ & $\mathbf{4}$ & $\mathbf{5}$ \\
\hline 1. Athletic & $\mathbf{0 . 7 8}$ & & & & \\
2. Academic & $.39^{* *}$ & $\mathbf{0 . 8 9}$ & & & \\
& & & & & \\
3. Financial Aid & $.31^{* *}$ & $.27^{* *}$ & $\mathbf{0 . 8 5}$ & & \\
& & & & & \\
4. Coaching Staff & $.70^{* *}$ & $.30^{* *}$ & $.25^{* *}$ & $\mathbf{0 . 7 8}$ & \\
& & & & & \\
5. Social Atmo- & $.59^{* *}$ & $.53^{* *}$ & $.31^{* *}$ & $.47 * *$ & $\mathbf{0 . 8 1}$ \\
sphere & 2.99 & 3.80 & 3.60 & 3.20 & 3.09 \\
\hline $\begin{array}{l}\text { Mean } \\
\text { SD }\end{array}$ & 0.66 & 0.66 & 1.09 & 0.82 & 0.60 \\
Number of items & 8 & 17 & 4 & 6 & 16 \\
\hline
\end{tabular}

Note. ${ }^{* *} p<.01 ;{ }^{*} p<.05$

The only other demographic variable with which MANOVA results revealed significant differences $(p<.05)$ and significant between-subjects effects was players' reported level of recruitment (Wilks' $=.04, F(5,494)=2.93, \mathrm{p}<.000)$. Between subjects effects tests for recruitment status showed significant differences $(\mathrm{p}<.05)$ with the coaching staff $(F(4,498)=7.93, \mathrm{p}<.000)$, and athletic $(F(4,498)=5.06, \mathrm{p}<.001)$. Players who reported not being recruited to play basketball indicated that the coaching staff and athletic factors were both significantly less important than other factors were in the process of making a decision with regard to their college selection.

\section{Discussion}

The purpose of this research was to examine the relative importance of a variety of factors which affect the college selection of NCAA DIII men's basketball players. The present college selection findings where the athletes in this sample rated academic factors as most important are consistent with results from prior studies of student-athlete college selection (Glasby, 2014; Kankey \& Quarterman, 2007; Mathes \& Gurney, 
1985; Pauline, 2010; Pauline et al., 2008). With basketball players across all NCAA divisions, Glasby (2014) found that basketball players perceived academics to be very/most important in their decision-making process, but DIII athletes perceived academics to be more important than DI or DII athletes. Within DIII athletics, where no athletic scholarships are available, these results indicate that the academic reputation and opportunities provided at a college or university outweigh other factors such as athletics and financial aid.

The results also revealed that DIII men's basketball players reported several factors that had less bearing in their college selection process. Media coverage, alumni in professional sports, and team sponsorships were all identified as comparatively less influential factors. These athletic factors being low in comparative importance is consistent with previous findings (Pauline, 2010). In DIII athletics, these factors are relatively unimportant in general, not just to men's basketball players; previous research found that media coverage and professional sport aspirations were considered a smaller part of athletes' decision-making processes at the DIII level than with athletes in DI or DII (Covell, Pelosi, \& Lemoi, 2013). Sponsorships and media coverage are also usually factors that can be seen at higher levels (i.e. DI), but most DIII schools have few if any sponsors and get relatively little media coverage. These are characteristics that make DIII uniquely different than DI athletics.
Although previous college selection research has found a variety of factors matter to college athletes (Magnusen et al., 2014b), the results with this sample are consistent with several studies that found career opportunities to be the most important factor (Kankey \& Quarterman, 2007; Pauline, 2010). The head coach has also been found to be a key factor in college selection (Goss et al., 2006; Letawsky et al., 2003; Kankey \& Quarterman, 2007; Mathes \& Gurney, 1985; Pauline, 2010) and the athletes in this sample rated the head coach as the top athletic factor and a top ten factor in their college selection.

For DIII men's basketball players, academics matter in their college selection. This is particularly interesting in that men's basketball players, who along with football players, have been found to make decisions due to athletic factors (Dumond et al., 2008), demonstrated contrasting values in the findings from the present study. Even at the DIII level, men's basketball and football are lumped together as revenue sports (Gabert et al., 1999), but if these groups act similarly, it would be expected to see this sample choose athletic factors first as has been found previously with gridiron athletes (Gabert et al., 1999; Stotlar, 1976). However, Konnert \& Giese (1987) also found DIII men's basketball players valued academics most in their college selection. These findings suggest that DIII basketball players may value different categories than DI revenue sport athletes and that those who are in DIII to begin with may 
be looking for a different experience. This suggests that talent may not be as important for DIII men's basketball coaches in the recruiting process as it is identifying what a recruit values most and is looking for in his college athlete experience.

The second purpose was to examine the college selection factors according to type of school they attended. While the differences were partially significant within this sample there were several differences worth highlighting. First, the players who valued athletic factors least in the decision-making were players at highly selective national liberal arts colleges, and the players who valued athletics the most were players at regional colleges. Regional colleges have a focus primarily on undergraduate education but grant less than half of their degrees in liberal arts disciplines (Morse et al., 2017). As such, regional colleges offer a high percentage of degrees in practical fields that can lead to jobs immediately for their students. According to US News \& World Report, regional colleges typically include colleges with higher acceptance rates, and draw students who originally live near the college. Similar to the comparison of DI to DIII recruits, present findings suggest that there may be a significant difference in values between athletes looking at these two schools. Coaches at highly selective national liberal arts colleges who want to maximize efficiency would likely be better served to drop a player from their recruiting list whose recruiting list includes regional colleges. This study to suggests that DIII male basketball players who end up at regional colleges might be thinking more about attending college close to home or about other athletic factors as opposed to academics. Regional colleges might have stronger local reputations despite being categorized differently in a national publication such as US News \& World Report.

The results according to type of school suggest that basketball players at Top 25 National Liberal Arts colleges were significantly less concerned with financial aid than all other groups. Having a pool of players who were less concerned about money supports a growing trend among Top 25 National Liberal Arts colleges that more and more athletes come from wealthy, affluent families who can afford to pay $\$ 50,000 /$ year in tuition, which is a result of a decrease in the discount rate at colleges and universities nationwide. As admission to these schools has become more competitive, and the cost of attendance continues to increase (Greenfield, 2015), so too has the need for students who can pay their own way. These results suggest that there are some differences according to type of school. Given the wide range in school sizes in DIII (Goss et al., 2006), the differing missions, and the fact that athletic scholarships are not allowed, understanding DIII college athlete selection warrants its' own attention without being compared to what happens in scholarship divisions. Beliefs about college selection decisions according to type of 
school seem to be different, and this too warrants additional attention.

Two interesting findings were revealed through the third purpose of this study. First, with regard to financial aid status, basketball players from wealthy families (circled: you or your family pays full tuition/room and board) were unconcerned with financial aid, while players who reported attending their current school on a full scholarship placed higher value on financial aid in their decision making. The financial aid component was highly important for some athletes in this sample and irrelevant for others. While DI has an even playing field in this realm, endowments, cost of attendance, budgets, and other resources at each institution vary wildly in DIII. This means that some coaches are forced to recruit to a financial demographic that would fit their circumstances. This leads some coaches at expensive schools to recruit very wealthy or very poor athletes, while other coaches can recruit anyone regardless of family income. Secondly, players who were not recruited did not place value on the coaching staff or their athletic experience as compared to others who were recruited.

\section{Limitations \& Future Directions}

There were several limitations in the present study. First, the IFSSA-R (Pauline, 2010) was originally used in a comparison of influential factors in college selection for lacrosse players playing on DI, DII, and DIII teams. As a result, the items were meant for a comparison across divisions. As the present study was focused solely within DIII, it is possible that some of the 51-items included really do not apply to the college selection of basketball players at the DIII level. Additional research in DIII athletes and in men's basketball is needed, and if the current findings from this study were replicated, the current results would be more generalizable. Second, as previously noted (Pauline, 2010), basketball players at all different points in their academic careers were included in this study and seniors may recall their college selection factors differently than freshman who more recently made this choice.

Regarding the influential factors of college selection in DIII, future investigations should consider what is it about DIII men's basketball players that makes them value academics in their college selection above all else; and whether DIII athletes in other sports similarly value academics. Collecting data from student-athletes in a singular athletics department would provide an overview of why athletes had selected that specific school. What would a comparison between schools or genders reveal? Comparing multiple DIII institutions would provide a unique cross-sectional comparison that could consider gender, sport, and other delimiting factors. While the college selection process is of importance to coaches and college administrators, connecting student-athlete college selection research, and more information on why athletes make their college decision, with student-athlete retention 
research would be valuable. Future qualitative research in college selection and DIII recruiting would also add a rich perspective to the existing body of literature.

\section{Practical Implications \& Conclusions}

In DIII men's college basketball, recruiting can be a daunting task for programs (Johnson, 2010) where only one or two full-time coaches are attempting to complete the jobs that coaches at other levels do with more resources at their disposal and scholarships to offer. For greater efficiency, one recommendation is to pay attention to the detail of their recruiting questionnaire. Believing that this is just a form that athletes can fill out online to submit their contact information would be missing an opportunity. Coaches should avoid generic questionnaires and should ask questions about types of schools athletes are interested in and why; they should ask questions about the importance of academics, the coaching staff, or the athletic facilitates; and they should work to gather accurate financial information about their recruits' families as early as they can in the process. Coaches who can use this information to identify which recruits are most likely to attend the school at the end of the process, earlier on, will be able to spend time wisely and efficiently earlier in the recruiting process.

Many colleges/universities have academic degrees that they are part of their reputation. Reputation is important for coaches to incorporate at all stages in the recruiting process and this has been found to have an influence in recruiting (Magnusen et al., 2017; Magnusen et al., 2018). While this seems logical, DIII coaches often get enamored with a player who will help their team regardless of that recruits' academic interests. Findings from this study suggest that coaches who pass on a good player with academic interests incongruent with the schools' notable programs will be able to more efficiently manage his/her time, even if this means passing on an athletically gifted individual. This might also mean waiting until that recruit visits campus before spending efforts chasing a recruit with different academic interests. Coaches should be wary of having too many of these recruits, or any, on their active lists so time can be spent on recruits with a greater likelihood of attending the school.

Coaches should also work with their institution to make sure that they understand the uniqueness of the type of school they are recruiting to. Embracing which type of school a coach is recruiting from will help coaches identify the right prospects earlier and spend their time more efficiently. While coaches might want to recruit talented basketball players who might be less likely to attend their school, their efficiency as a recruiter depends on paying attention to the type of school they represent, selling relevant academic factors to recruits, and understanding the characteristics of who they are recruiting. Effectively doing these things may make the difference between spending time recruiting a great player 
who selects a different school or finding the right DIII athlete for their school and their program.

\section{References}

Alger, T. (2013). Playing the recruiting game in Division III. The Oregonian/OregonLive.com. Retrieved from https://www.oregonlive.com/ forest-grove/index.ssf/2013/01/playing_the_recruiting_game_in.html

Behling, O., Labovitz, G., \& Gainer, M. (1968). College recruiting: A theoretical base. Personnel Journal, 47, 13-19.

Caro, C.A. (2012). College football success: The relationship between recruiting and winning. International Journal of Sport Sciences \& Coaching, 7(1), 139-152.

Covell, D.D., Pelosi, M.K., \& Lemoi, J. (2013). Joining the team: A case study identifying and assessing critical factors influencing NCAA Division III student-athlete matriculation. Journal of Applied Sport Management, 5(1), 3156.

Cronbach, L. J. (1951). Coefficient alpha and the internal structure of tests. Psychometrika, 16(3), 297-334.

Czekanski, W.A., \& Barnhill, C.B. (2015). Recruiting the studentathlete: An examination of the college decision process. Journal for the Study of Sports and Athletes in Education, 9(3), 133-144.

Day, K. (2011). Determining important collegiate-choice factors in the recruitment of prospective student athletes. Retrieved from ProQuest digital dissertations. (UMI EP33690).

Dorsey, R. (2017, Feb 17). AAU changing the landscape of modern basketball. University Wire. Retrieved from https://unco.idm.oclc.org/ login?url=https: // search-proquest-com.unco.idm.oclc.org/ docview/1870016038?accountid $=12832$

Doyle, C. A., \& Gaeth, G. J. (1990). Assessing the institutional choice process of student-athletes. Research Quarterly for Exercise and Sport, 61(1), 85-92.

Dumond, J.M., Lynch, A.K., \& Plantania, J. (2008). An economic model of the college football recruiting process. Journal of Sports Economics, 9, 67-87.

Evans, B. \& Pitts, J.D. (2018). The determinants of NCAA basketball recruiting outcomes. Applied Economics Letters, 24(5), 351-354.

Fink, J.S., Pastore, D.L., \& Riemer, H.A. (2003). Managing employee diversity: Perceived practices and organisational outcomes in NCAA division III athletic departments. Sport Management Review, 6(2), 147-168.

Gabert, T., Hale, J., and Montalvo, G. (1999). Differences in college choice factors. College Admission, 16, 20-29.

Galleske, J. (2012, December 5). St. Ben's sets sights beyond border. Retrieved from http://www.d3hoops.com/ columns/around-the-region/midwest-west/index

Glasby, M.K. (2014). Factors influencing the college/ university choice of high school 
boys' basketball players. (Unpublished master's thesis). Howard University, Washington, D.C.

Goss, B.D., Jubenville, C.B., \& Orejan, J. (2006). An examination of influences and factors on the institutional selection processes of freshman student-athletes at small colleges and universities. Journal of Marketing for Higher Education, 16(2), 105-134. doi: 10.1300/J050v16n02_05

Greenfield, J.S. (2015). Challenges and opportunities in the pursuit of college financial literacy. High School Journal, 98(4), 316-334.

Hambleton, K. (2010, February 1). Recruiting can have domino effect on the small schools. Lincoln Journal Star, p. C.1.

Harris, J.S. (2018). State of play: How do college football programs compete for student athletes? Review of Industrial Organization, 52(2), 269-281.

Johnson, J. (2010, February 2). Recruiting never ends in division III: D-III coaches working hard. McClatchy - Tribune Business News, no pages.

Judson, K.M., James, J.D., \& Aurand, T.W. (2005). Building a successful American collegiate athletic program: Recruiting student-athletes from lower profile sports. International Journal of Sport Management, 6, 122-140.

Kane, C. (2009, August 22). Athletic scholarships available if you do homework: 8 ways to increase your odds at funds. Chicago Tribune. Retrieved from http://articles. chicagotribune.com/2009-08-22/

sports/0908210429

Kankey, K., \& Quarterman, J. (2007). Factors influencing the university choice of NCAA division I softball players. The SMART Journal, 3(2), 3549.

Konnert, W., and Giese, R., (1987). College choice factors of male athletics at private NCAA Division III institutions. College and University, 63, 33-44.

Letawsky, N.R., Schneider, R.G., Pedersen, P.M., \& Palmer, C.J. (2003). Factors influencing the college selection process of student-athletes: Are their factors similar to non-athletes? College Student Journal, 37(4), 604-610.

Magnusen, M.J., Kim, J.W., McAllister, C.P., Perrewé, P.L., \& Ferris, G.R. (2018). She got game: Investigating how reputation can be leveraged to improve recruiting effectiveness in National Collegiate Athletic Association women's basketball. International Journal of Sports Science \& Coaching, 13, 179-185.

Magnusen, M.J., Kim, Y.K., \& Perrewé, P.L. (2014a). Gaining a competitive edge when recruiting student-athletes: The role of political skill. International Journal of Sports Science \& Coaching, 9, 1291-1310.

Magnusen, M.J., Kim, Y.K., Perrewé, P.L., \& Ferris, G.R. (2014b). A critical review and synthesis of student-athlete college choice factors: Recruiting effectiveness in NCAA sports. International Journal of Sports Science \& Coaching, 9, 1265-1286. 
Magnusen, M.J., McAllister, C.P., Kim, J.W., Perrewé, P.L., \& Ferris, G.R. (2017). The reputation playbook: Exploring how reputation can be leveraged to improve recruiting effectiveness in NCAA men's basketball. Journal of Applied Sport Management, 9, 11-24.

Mathes, S., \& Gurney, G. (1985). Factors in student athletes' choices of colleges. Journal of College Student Personnel, 26(4), 327-33.

Morse, R., Brooks, E., \& Mason, M. (2017, September 11). How U.S. News Calculated the 2018 Best Colleges Rankings. Retrieved from https://www.usnews.com / education/best-colleges/ articles/how-us-news-calculated-therankings

NCAA DI Manual (2017). 2017-2018 NCAA Division I Manual-August version. Retrieved from https://www. ncaapublications.com/p-4511-20172018-ncaa-division-i-manual-augustversion-available-august-2017.aspx NCAA Recruiting Facts (2018). NCAA recruiting facts: College sports create a pathway of opportunity for student-athletes. Retrieved from https://www.ncaa.org/_ sites/default/files/Recruiting $\% 20$ Fact $\% 20$ Sheet $\% 20 W E B$.pdf

Nunnally, J.C. (1978). Psychometric theory. New York: McGraw-Hill.

Pauline, J.S. (2010). Factors influencing college selection by NCAA division I, II, and III lacrosse players. The ICHPER-SD Journal of Research in Health, Physical Education, Recreation, Sport \& Dance, 5(2), 62-69.
Pauline, J.S., Pauline, G.A., \& Allen, C. (2008). Factors influencing college selection by NCAA division I, II, and III softball student-athletes. Journal for the Study of Sports and Athletes in Education, 2(3), 363-378.

Pauline, J.S., Pauline, G.A., \& Stevens, A.J. (2004). Influential factors in the college selection process of baseball student-athletes. Journal of Contemporary Athletics, 1, 153-166.

Pennington, B. (2006, May 21). Results can be jarring as recruiting carousel stops. The New York Times, pp. 8-1, 8-6.

Rhee, Y.C., Barnes, J., Kim, W., \& Carroll, D. (2018). Motivational factors influencing university selection of non-revenue generation sport student-athletes. Journal of Contemporary Atbletics, 12(3), 209-236.

Schmidt, W.D., Piencikowski, C.L., \& Vandervest, R.E. (2005). Effects of a competitive wrestling season on body composition, strength, and power in national collegiate athletic association division III college wrestlers. Journal of Strength and Conditioning Research / National Strength \& Conditioning Association, 19(3), 505-508. doi: 10.1519/00124278-200508000-00004

Schrotenboer, B. (2012, September 25).

Division III lends perspective for some fleeing big time. USA Today, p. $02 \mathrm{c}$.

Stotlar, D.K. (1976). Factors influencing western section Pennsylvania State Colleges Athletic Conference football players in their selection of a college (Unpublished 
master's thesis). Slippery Rock State

College, Slippery Rock, PA.

Treadway, D.C., Adams, G., Hanes, T.J.,

Perrewe, P.L., Magnusen, M.J., \&

Ferris, G.R. (2014). The roles of re-

cruiter political skill and performance

resource leveraging in NCAA football

recruitment effectiveness. Journal of

Management, 40, 1607-1626.

Treme, J., Burrus, R., \& Sherrick, B.

(2011). The impact of recruiting on

NCAA basketball success. Applied

Economics Letters, 18(9), 795-798. 